\title{
Immunohistochemical Localization of Vascular Factors in Tooth Germ of Amphibian (Cynops pyrrhogaster)
}

\author{
Localización Inmunohistoquímica de Factores Vasculares en \\ Germen Dentario de Anfibios (Cynops Pyrrhogaster)
}

Yoko Miwa ; Kingo Suzuki \& Masataka Sunohara

MIWA, Y. ; SUZUKI, K. \& SUNOHARA, M. Immunohistochemical localization of vascular factors in tooth germ of amphibian (Cynops pyrrhogaster). Int. J. Morphol., 39(2):625-629, 2021.

SUMMARY: Vascular endothelial growth factor (VEGF) and its receptor, VEGFR-2, are known to regulate blood vessel endothelium growth. They play important role in human and rodents teeth development. In newt jaws, there are sequential developmental teeth germs following behind the mature teeth. We examined the immunohistochemical localization of VEGF and its receptor and showed the specific expression pattern of VEGF and VEGF receptor in Cynops pyrrhogaster sequential tooth development. The intensity of immunoreactivity for VEGF in the inner enamel epithelium was weaker than that in the outer enamel epithelium in the dentine matrix formation and mineralization stages. Finally, at the enameloid maturation and enamel-like matrix formation stage, immunoreactivity for VEGF in inner enamel epithelium was stronger than in the outer enamel epithelium. The intensity of immunoreactivity for VEGFR-2 was positive for the outer enamel epithelium throughout tooth development. The crown sides of the odontoblasts were stained especially strongly for VEGF and VEGFR-2 during the dentine matrix formation and mineralization stage of the enameloid maturation and enamellike matrix formation stage. We postulate that the expression of VEGF in the inner enamel epithelium and odontoblast widely effects tooth development in newts, as well as in human and rodents.

KEY WORDS: Vascular endothelial growth factor; Amphibian; Tooth germ.

\section{INTRODUCTION}

The tooth of Amphibian is polyphyodonty and show a series of teeth germ developed in their jaws at the sequential area at the same time. Tooth development in Japanese newts Cynops pyrrhogaster occurs in the following three stages: (1) the enameloid matrix formation stage, in which tooth shape formation begins at the inner enamel epithelium in the enamel organ; (2) the dentine matrix formation and mineralization stage, in which collagen fibers that are secreted by odontoblasts and oriented parallel to the tooth surface are subsequently mineralized; and (3) the enameloid maturation and enamellike matrix formation stage, in which the inner enamel epithelium forms an enamel-like matrix and a mineralized shaft dentin by the distal cell membrane. Dentinogenesis starts when odontoblasts form collagen matrices that are involved in the formation of a considerable portion of the enameloid matrix. In newts, this includes the collagen fibrils in the zone between enamel and dentin (Kogaya, 1999).
VEGF-A is a key regulator of blood vessel endothelial growth (subsequently termed only as VEGF) (Rodríguez-Núñez et al., 2015). In adults, VEGF controls angiogenesis (Okada et al., 2010), wound healing (Brown et al.,1992) and inflammatory diseases (Nicosia, 1998). VEGFR-2 is a major mediator of the mitogenic and angiogenic effects of VEGF. In addition to its role in vascularization, an increased level of VEGF mRNA expression was seen in the tooth germ of inner enamel epithelium in rat embryo (Aida et al., 2005). Immunohistochemical analysis has shown that expression of VEGF was prominent in tooth germ and mesenchyme during the initial stages of crown mineralization in humans (Mastrangelo et al., 2005; Brizuela et al., 2013). Furthermore, immunoreactivity to VEGF and its receptor VEGFR-2 were positive in the inner enamel epithelium during the cap stage (tooth shape formation begins at the enamel epithelium in the enamel organ) and at the late bell

Department of Anatomy, School of Life Dentistry at Tokyo, Nippon Dental University 1-9-20 Fujimi, Chiyoda-ku, Tokyo 102 -8159, Japan.

This study was supported by Young Scientists Grant No. (B) 23792117 from the Ministry of Education, Culture, Sports, Science, and Technology, of Japan. 
stage (tooth germ formation and mineralization). The intensity of VEGF immunoreactivity was mainly positive but was weak for VEGFR-2. The intensity of VEGF and VEGFR-2 expression in odontoblasts increases from cap stage to late bell stage (Miwa et al., 2008). The purpose of the present study was to reveal the expression of VEGF and VEGFR-2 in newt tooth development that exhibits various developmental stages of tooth germs at the same individual at the same section.

\section{MATERIAL AND METHOD}

Newt specimens. Five adult specimens of the Japanese newt Cynops pyrrhogaster collected at Tohoku Prefecture (5.0 g average weight) were purchased from Nippon BioSupp. Center in Tokyo, Japan. They were maintained at $25^{\circ} \mathrm{C}$ in a 14 hour light/10hour dark cycle until use (Tsuruda et al., 2002). They were processed according to the provisions of "Regulations for Animal Experimentation in The Nippon Dental University School of Life Dentistry at Tokyo" and according to the relevant regulations, the study of amphibian is exempt from the approval requirement.

Preparation of tissue sections. Specimens of the head of Cynops pyrrhogaster were fixed for $24 \mathrm{~h}$ in a solution of 4 $\%$ paraformaldehyde (PFA) and demineralized with $4 \%$ ethylene diamine tetra acetic (EDTA) acid for a week at 4 ${ }^{\circ} \mathrm{C}$. These specimens were fixed for an additional $30 \mathrm{~min}$ in a solution of $4 \%$ PFA and soaked in $30 \%$ sucrose in $0.2 \mathrm{M}$ phosphate buffer ( $\mathrm{pH}$ 7.2). They were then embedded into OCT compound (Tissue Tek II, Sakura Finetechinical Co., Ltd, Tokyo, Japan), frozen in liquid nitrogen and stored at $-80^{\circ} \mathrm{C}$ until use. Frozen sections (about $10 \mu \mathrm{m}$ thick) of the samples were cut and fixed for an additional $10 \mathrm{~min}$ in a solution of $4 \%$ PFA. These sections were incubated with 50 -fold diluted normal goat serum in phosphate-buffered saline (PBS; pH 7.2; $0.05 \%$ Tween 20 was added in order to prevent subsequent non-specific absorption of antibodies) for $1 \mathrm{~h}$ at room temperature. After separate incubation with antibodies against VEGF (1:100; \#RB-222; Lab Vision Corp, CA, USA) and VEGFR-2 (1:100; ab2349; Abcam Ltd, Cambridge, UK), these sections were washed 3 times for 5 min with PBS. Following the manufacturer's protocol, these sections were incubated with biotinylated antibodies against rabbit IgG (Vectastain Elite ABC Kit; Vector Laboratories, Burlingame, CA., USA). Then, the specimens and controls (treated with normal rabbit serum in PBS) were washed 3 times for 5 min with PBS in $0.05 \%$ Tween 20. Finally, they were incubated with a mixture of reagents from an elite $\mathrm{ABC}$ kit that contained $0.02 \% \mathrm{H}_{2} \mathrm{O}_{2}$ and 0.1 $\%(1 \mathrm{mg} / \mathrm{ml})$ diaminobenzidine tetrahydrochloride (in 0.1
$\mathrm{M}$ Tris- $\mathrm{HCl}, \mathrm{pH}$ 7.2). The sections were mounted with Bioleit (Kokenn, Tokyo, Japan) and observed under a light microscope (Olympus, Tokyo, Japan). Tooth development stages were decided as previously reported (Kogaya). Immunohistochemical expression was quantified using photo-analysis computer software (WinRoof, Mitani co, Japan) and classified as follows: (-) negative (less than -10 $\%$ of blood vessel endothelium intensity), ( \pm ) moderately positive (-10 to $10 \%$ of blood vessel endothelium intensity), (+) positive (10-50\% of blood vessel endothelium intensity), and (++) strongly positive (more than $50 \%$ of blood vessel endothelium intensity).

\section{RESULTS}

VEGF expression during the dentine matrix formation and mineralization stage is magnified in Figure $1 \mathrm{C}$ and summarized in Table I. During the enameloid matrix formation stage, tooth shape formation began at the inner enamel epithelium in the enamel organ, which revealed faint VEGF expression in the inner dental epithelium of the tooth bud. At the dentine matrix formation and mineralization stage, VEGF exhibited immunolocalization on the top of the inner enamel epithelium surrounding a mineralized tooth and faint expression in the outer enamel epithelium. VEGF was also strongly expressed on the crown side of odontoblasts. At the enameloid maturation and enamel-like matrix formation stage, VEGF exhibited faint immunolocalization to most of the outer enamel epithelium. There were strong reactions to inner enamel epithelium surrounding a mineralized tooth and odontoblasts. Positive reactions were counted as equal staining of VEGF immunolocalization to vascular endothelium.

VEGFR-2 expression is shown in Figures 1A and B and summarized in Table I. At the enameloid matrix formation stage, VEGFR-2 was expressed in the outer enamel epithelium remarkably with faint accumulation in the inner enamel epithelium. At the dentine matrix formation and mineralization stage, VEGFR-2 exhibited immunolocalization predominantly to the top of outer enamel epithelium surrounding a mineralized tooth and to the crown side of odontoblasts; however, no accumulation was observed in the inner enamel epithelium. At the enameloid maturation and enamel-like matrix formation stage, VEGFR-2 was expressed primarily in the outer enamel epithelium, and strong accumulation was observed in the crown side of the odontoblast. There was no notable expression in the inner enamel epithelium. Positive reactions were determined as the staining of VEGFR-2 immunolocalization in the vascular endothelium. 


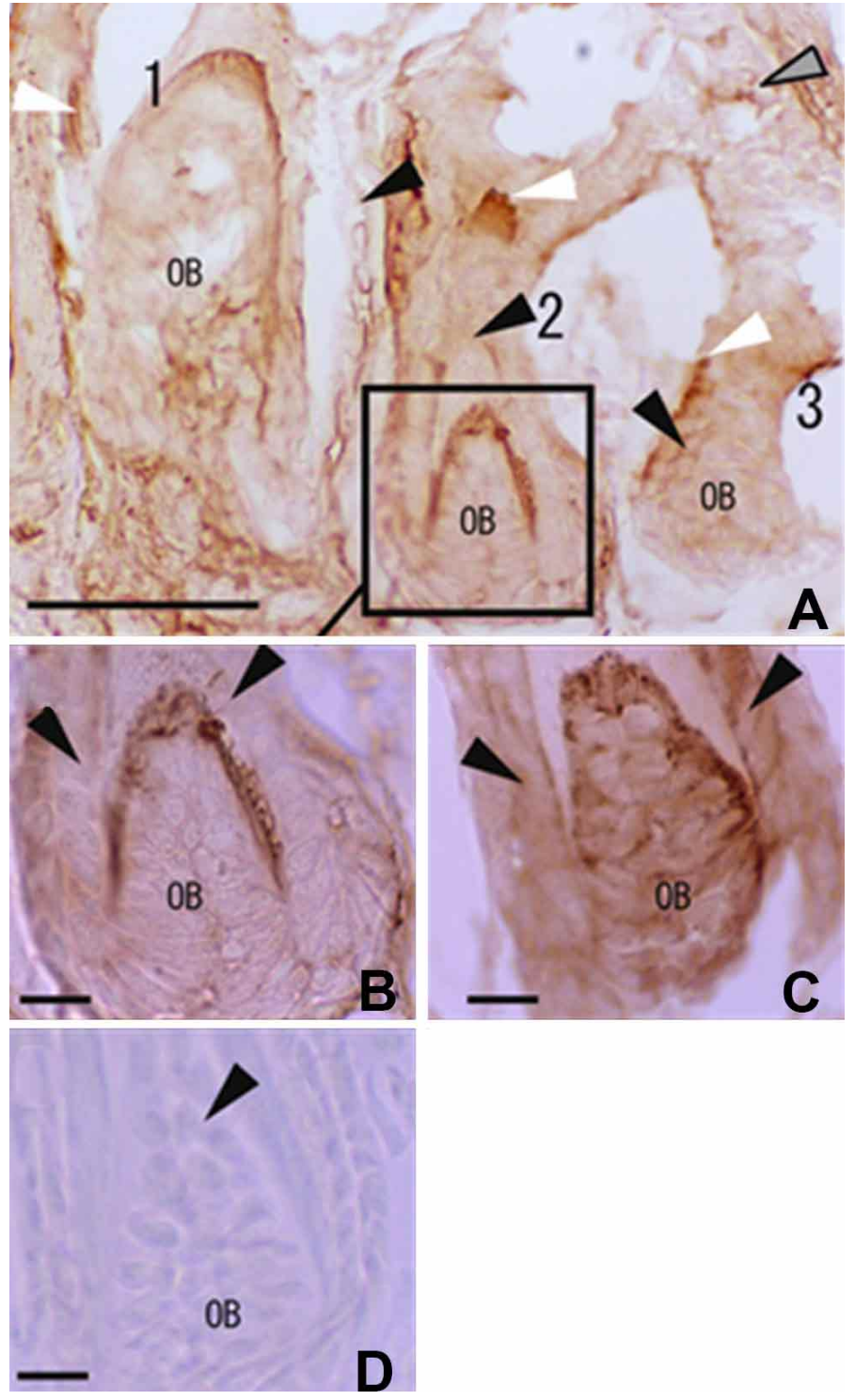

Table I. The immunohistochemical analysis of VEGF and VEGFR-2 in sagitally sectioned Cynops pyrrhogaster dental germ in maxilla.

\begin{tabular}{lcc}
\hline Antibody & VEGF & VEGFR-2 \\
\hline Enamel oid matrix formation stage & & \\
Outer enamel epithelium & \pm & ++ \\
Inner e namel epithelium & \pm & \pm \\
Odontoblasts & \pm & \pm \\
Surrounding bone & & \pm \\
Dentine matrix formation and mineralization stage & \pm & \\
Outer enamel epithelium & ++ & - \\
Inner e namel epithelium & \pm & ++ \\
Odontoblasts & & \pm \\
Surrounding bone & & \\
Enamel oid maturation and enamel-like matrix formation & \pm & ++ \\
stage & ++ & \pm \\
Outer enamel epithelium & ++ & ++ \\
Inner e namel epithelium & \pm & \pm \\
Odontoblasts & & \\
Surrounding bone & &
\end{tabular}

Fig. 1. Immunohistochemical characterization of Cynops pyrrhogaster teeth development. A. VEGFR-2 expression in sequential tooth development. 1. Analysis of sagitally- sectioned teeth at the enameloid maturation and enamel-like matrix formation stage. The inner enamel epithelium forms the enamel-like matrix and the mineralized shaft dentin by the distal cell membrane stage. VEGFR-2 exhibits immunolocalization to the outer enamel epithelium, faintly surrounding a mineralized tooth. 2. At the dentine matrix formation and mineralization stage; collagen fibers are secreted by odontoblasts and oriented parallel to the tooth surface are subsequently mineralized; VEGFR-2 exhibits immunolocalization to the top of the outer enamel epithelium surrounding a mineralized tooth. 3. At the enameloid matrix formation stage, tooth shape formation begins at the inner enamel epithelium in the enamel organ. VEGFR 2 is primarily expressed in the crown side of odontoblasts. B. Magnification of tooth germ indicated in A reacted with anti-VEGFR-2 antibody. C. Magnification of tooth germ indicated in A reacted with anti-VEGF antibody. D. Negative control. bar=100um in A, bar=10um in B. White arrowhead: outer enamel epithelium; Black arrow head: inner enamel epithelium; Gray arrowhead: vascular endothelium in surrounding bone; OB: odontoblasts.
VEGF and VEGFR-2 expressions were quantified using a photo analysis computer software (Scion Image, Beta 4.03,Frederick, Md., USA) and are classified as follows: (-) negative(less than $-10 \%$ of blood vessel endothelium intensity), $( \pm)$ moderately positive (-10 to less than $100 \%$ of blood vessel endothelium intensity), (+) positive (100 to less than $150 \%$ of blood vessel endothelium intensity), and (++) strongly positive (more than $150 \%$ of blood vessel endothelium intensity). The levels of reactive intensity for immunohistochemical staining for VEGF or VEGFR-2 on the blood vessel endothelium in surrounding bone were considered as $(+)$. 


\section{DISCUSSION}

Enamel epithelium of tooth germ surface. In rats, an increased level of VEGF mRNA expression was seen in the outer enamel epithelium rather than in the inner enamel epithelium at cap stage, which is considered the dentine matrix formation and mineralization stage in Cynops pyrrhogaster tooth development. In early to late tooth development stages, there was increased VEGF mRNA expression prominent in the inner enamel epithelium (Aida et al.). In agreement with these results from a rodent model, our results show that the intensity of immunoreactivity for VEGF in the inner enamel epithelium was weaker than it was in the outer enamel epithelium during dentine matrix formation and mineralization. VEGF accumulation increased prominently in the inner enamel epithelium throughout tooth development. Finally, during the enameloid maturation and enamel-like matrix formation stage, immunoreactivity for VEGF in the inner enamel epithelium was stronger than in the outer enamel epithelium.

Our results also show constant VGFR-2 positive reaction to the outer enamel epithelium throughout tooth development. However, weak or negative expression was detected in the inner enamel epithelium. This result is different from the human tooth germ at the late bell stage (which corresponds to the enameloid maturation and enamellike matrix formation stage). The expression of VEGF and VEGFR-2 were almost constantly positive in the human inner enamel epithelium (Miwa et al.). At first, we assumed that the tooth development of the polyphyodont Cynops pyrrhogaster would resemble that of humans, who are diphyodonts and develop deciduous and permanent teeth. The epithelium-derived inner and enamel epithelium, the expressions of VEGF and VEGFR-2 in Cynops pyrrhogaster teeth are thought to resemble the expressions of these proteins in tooth germ of rat, which has only a single set of permanent teeth (monophyodonty). This may indicate that the regulation of VEGF and VEGFR-2 expression in the enamel epithelium is specific to special term or cells in the formation of tooth shape for different species.

Odontoblasts inside the tooth germ. In addition to its presence in epithelium-derived enamel epithelium and ameloblasts, immunohistochemical localization of VEGF has also been detected in the mesenchyme-derived odontoblasts in human third molar teeth germs at the initial stage of crown mineralization (Mastrangelo et al.). In humans, positive reactions for VEGF and VEGFR-2 in odontoblasts increased from the cap stage to late bell stages (Miwa et al.). In our study, the crown side of the odontoblast was stained especially strongly for VEGF and VEGFR-2 in the dentine matrix formation and mineralization stage and the enameloid maturation and enamel-like matrix formation stage. The crown sides of odontoblasts secrete the dentine matrix. The strong expression of VEGF and VEGFR-2 in odontoblasts may indicate that VEGF signaling was transmitted by their VEGFR-2 via a paracrine regulation system that modulates the secretion of the dentine matrices.

The bones surrounding tooth germ. We also detected immunohistochemical localization of VEGF and VEGFR-2 in surrounding bones (Table I). They may influence the vascular supply of the teeth germ sequential teeth germ generation smoothly.

Mammals, including humans, cannot generate teeth after they had permanent tooth. However, the expression of VEGF and VEGFR-2 were also expressed at the sequential tooth germ generation in Cynops pyrrhogaster. We assume that the VEGF plays a significant role for teeth germ generation in vertebra and it it may affect the tooth generation in mammals using same system. In future we want to develop our research for other amphibian species in south America.

MIWA, Y. ; SUZUKI, K. \& SUNOHARA, M. Localización inmunohistoquímica de factores vasculares en germen dentario de anfibios (Cynops pyrrhogaster). Int. J. Morphol., 39(2):625-629, 2021.

RESUMEN: Se sabe que el factor de crecimiento endotelial vascular (VEGF) y su receptor, VEGFR-2, regulan el crecimiento del endotelio de los vasos sanguíneos. Desempeñan un papel importante en el desarrollo de los dientes humanos y de los roedores. En las mandíbulas de tritón, hay gérmenes dentales de desarrollo secuenciales que siguen a los dientes maduros. Examinamos la localización inmunohistoquímica de VEGF y su receptor y mostramos el patrón de expresión específico de VEGF y receptor de VEGF en el desarrollo secuencial de dientes de Cynops pyrrhogaster. La intensidad de la inmunorreactividad para VEGF en el epitelio interno del esmalte era más débil que en el epitelio externo del esmalte en las etapas de formación y mineralización de la matriz de dentina. Finalmente, en la etapa de maduración del esmalte y de formación de la matriz similar al esmalte, la inmunorreactividad para VEGF en el epitelio interno del esmalte fue más fuerte que en el epitelio externo del esmalte. La intensidad de la inmunorreactividad para VEGFR2 fue positiva para el epitelio externo del esmalte durante el desarrollo del diente. Los márgenes de la corona de los odontoblastos se tiñeron especialmente para VEGF y VEGFR-2 durante la etapa de formación de la matriz de dentina y mineralización de la etapa de maduración del esmalte y la etapa de formación de la matriz similar al esmalte. Postulamos que la expresión de VEGF en el epitelio interno del esmalte y odontoblastos afecta ampliamente el desarrollo de los dientes en tritones, así como en humanos y roedores.

PALABRAS CLAVE: Factor de crecimiento vascular endotelial; Anfibio; Germen de diente. 


\section{REFERENCES}

Aida, M.; Irie, T.; Aida, T. \& Tachikawa, T. Expression of protein kinases $\mathrm{C}$ betaI, betaII, and VEGF during the differentiation of enamel epithelium in tooth development. J. Dent. Res., 84(3):234-9, 2005.

Brizuela C. C.; Galleguillos, G. S.; Carrión, A. F.; Cabrera, P. C.; Luz, C. P. \& Inostroza, S. C. Isolation and characterization of mesenchymal stem cells from human dental pulp and follicle. Int. J. Morphol., 31(2):73946, 2013.

Brown, L. F.; Yeo, K. T.; Berse, B.; Yeo, T. K.; Senger, D. R.; Dvorak, H. F. \& van de Water, L. Expression of vascular permeability factor (vascular endothelial growth factor) by epidermal keratinocytes during wound healing. J. Exp. Med., 176(5):1375-9, 1992.

Kogaya, Y. Immunohistochemical localisation of amelogenin-like proteins and type I collagen and histochemical demonstration of sulphated glycoconjugates in developing enameloid and enamel matrices of the larval urodele (Triturus pyrrhogaster) teeth. J. Anat., 195(Pt. 3):45564, 1999.

Mastrangelo, F.; Piccirilli, M.; Dolci, M.; Teté, S.; Speranza, L.; Patruno, A.; Gizzi, F.; Felaco, M.; Artese, L \& De Lutiis, M. A. Vascular endothelial growth factor (VEGF) in human tooth germ center. Int. $J$. Immunopathol. Pharmacol., 18(3):587-94, 2005.

Miwa, Y.; Fujita, T.; Sunohara, M. \& Sato, I. Immunocytochemical localization of vascular endothelial growth factor and vascular endothelial growth factor receptor- 2 of the human deciduous molar tooth germ development in the human fetus. Ann. Anat., 190(3):246$51,2008$.

Nicosia, R. F. What is the role of vascular endothelial growth factor-related molecules in tumor angiogenesis? Am. J. Pathol., 153(1):11-6, 1998.

Okada, Y.; Ueno, H.; Katagiri, M.; Oneyama, T.; Shimomura, K.; Sakurai, S.; Mataga, I.; Moride, M. \& Hasegawa H. Experimental study of antiangiogenic gene therapy targeting VEGF in oral cancer. Odontology, 98(1):52-9, 2010

Rodríguez-Núñez, I.; Romero, F.; González, M. \& Campos, R. R. Biology of vascular development: mechanisms in physiological conditions and shear stress. Int. J. Morphol., 33(4):1348-54, 2015.

Tsuruda, K.; Arakawa, O.; Kawatsu, K.; Hamano, Y.; Takatani, T. \& Noguchi, T. Secretory glands of tetrodotoxin in the skin of the Japanese newt Cynops pyrrhogaster. Toxicon, 40(2):131-6, 2002.

\author{
Corresponding author: \\ Yoko MIWA, Ph.D. DDS \\ Department of Anatomy \\ School of Life Dentistry at Tokyo \\ Nippon Dental University \\ 1-9-20 Fujimi, Chiyoda-ku \\ Tokyo $102-8159$ \\ JAPAN
}

\section{E-mail: yokoa1@tky.ndu.ac.jp}

Received: 19-12-2020

Accepted: 23-01-2021 